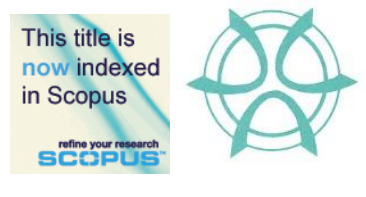

PLANNING MALAYSIA:

Journal of the Malaysian Institute of Planners

VOLUME 16 ISSUE 3 (2018) Page $69-82$

\title{
DEVELOPING A 3-D GIS MODEL FOR URBAN PLANNING. CASE STUDY: AMPANG JAYA, MALAYSIA
}

\author{
Mimi Zaleha Abdul Ghani' ${ }^{1}$, Yazid Sarkom² \& Zalina Samadi ${ }^{3}$ \\ ${ }^{1,2,3}$ Faculty of Architecture, Planning and Surveying \\ UNIVERSITI TEKNOLOGI MARA, MALAYSIA
}

\begin{abstract}
This paper aims to explore the rich potential of interactive visualisation environment integrating GIS for modelling urban growth and spatio-temporal transformation of Malaysian cities. As a case study example, authors consider a 3-D GIS model of Ampang Jaya, Selangor to investigate the techniques of data acquisition, data reconstruction from physical to digital, urban analysis and visualisation in constructing a digital model ranging from low to high geometric content including 2-D digital maps, digital orthographic and full volumetric parametric modelling. The key aspect of this virtual model is how it would assist in understanding the urban planning and design of Ampang Jaya by translating complex spatial information that are currently used by the authorities for planning activities such as maps, plans and written information into responsive, easily understandable spatial information. It could serve as a new platform to disseminate information about Ampang Jaya, bridge gaps among professionals involved in planning processes, improve communications among decision makers, stakeholders and the public as well as support decision making about the spatial growth of Ampang Jaya. Demonstrations of Ampang Jaya will also provide a clearer picture of the importance of ownership and control of 3-D models by local councils in empowering them in decision making, for example, in improving transparency, and avoiding misuse by project developers (Shiffer 1993; Sunesson et al., 2008). Such environment will improve the subsequent digital models and research in the area of urban design and planning in Malaysia where visual communication is pivotal.
\end{abstract}

Keywords: 3-D GIS, visualisation, planning support tool, communication platform, urban planning 
Mimi Zaleha Abdul Ghani, Yazid Sarkom, \& Zalina Samadi

Developing a 3-D GIS Model for Urban Planning. Case Study: Ampang Jaya, Malaysia

\section{INTRODUCTION}

The general aim of Virtual Ampang Jaya is to assist planning activities in Malaysia and promoting the advantage of a ready visualisation of complex 3-D information. It will suggest how complex city information could be held within a 3-D environment which can be visually seen and made interactive by means of stronger coupling; embedding the 3-D model within the functions of GIS system as a more advanced version of weaker coupling (Batty, 2012). The planning issues and challenges of the urban context would be considered before designing the strategies of developing a case study involving the processes of modelling, data acquisition, data reconstruction, and finally the 3-D visualisation that is effective in serving a sense of understanding of a larger context of the building and its surroundings (Herbet \& Xuwei, 2015).

In addressing the spatio-temporal transformation of Malaysian cities and towns, the government through its multimedia agency MDec is called upon to respond to the pressing need to develop expertise in the application of digital media in the Malaysian urban planning (Lee \& Ahmad, 2000). Currently, there is a lack of study integrating 2-D GIS and 3-D models in the context of Malaysian planning practices, which are distinctive in terms of their policy, social and cultural context and administration (Abdullah, Abdullah, \& Ibrahim, 2009; Rafi \& Rani 2008). Set as an experimental test pad in the uptake of digital and multimedia in Malaysia, Virtual Ampang Jaya will explore the GIS analytical and querying capabilities with interactive visualisation environment while demonstrating the usefulness of 3-D visualisation and GIS in planning.

\section{MOTIVATIONS}

Cities are highly complex systems and digital media offers a new understanding of urban problems. In understanding how cities operate and informing the planning and design process, various simulation models operating at different spatial scales and over different temporal period have been constructed over the last 50 years (Batty, 2012). Defined as "a city in which ICT is merged with traditional infrastructures, coordinated and integrated using new digital technologies" (Batty, 2012: 481), "smart cities" are amongst ambitious models developed to control the urbanisation processes to avoid future development failure from inefficient urban planning (Thuzar, 2012). While some adopt more sophisticated approaches such as "unified process" for standardise and effective system (Rong, Wu, \& Shang, 2017), others use less ambitious technological inventions such as Twitter data in developing a close and up-to-date connection to the city of Amsterdam involving a real-time system based analysis (ArribasBel, Kourtit, Nijkamp, \& Steenbruggen, 2015). Such responsive spatial information further enriches understanding of urban issues to better facilitate the planning process to produce better result and decisions. 
PLANNING MALAYSIA

Journal of the Malaysia Institute of Planners (2018)

The development of 3-D GIS is large scale and complex multidimensional involving many aspects and involving theories and technologies (Rong et al., 2017). Planning information can be easily understood and disseminated to residents as the virtual model translates complex city information that is usually tailored to a specific group of professionals into responsive spatial information that will be more easily understood by layman amongst stakeholders who are not taught to read coded information such as plans and maps. Highly realistic model is a successful method in communicating with the public and have been used in the Malaysian context in advertising new large cities. While visualisation is amongst the most powerful tool for promoting urban changes, city officials, urban planners and the general public must be able to visualise urban plans along with all the infrastructure that already exists (Lopes \& Lindström 2012). However, although studies on planning support system using 3-D visualisation and GIS are abundant, their role in the practice of urban planning since their emergence in the 1990s, and despite the long term use of 3-D visualisation tools in planning, is questionable. This could relate a wider range of problems including issues of developer and operator of the models, and whether the models enable new kinds of processes and new levels of engagement amongst users (Lopes \& Lindström, 2012), as well as many studies in planning support system are not integrating real-world practice as they mainly involve stand-alone projects (Brail \& Klosterman, 2001). Therefore, this study will involve real projects and the local planning authorities to help to demonstrate the true process and challenges of developing a 3-D visualisation and GIS model to enhance methods of current planning and consultation processes by decision makers and communicate with the various stakeholders including the public (Pietsch, 2000).

\section{THE PROPOSED VIRTUAL AMPANG JAYA}

As a planning support tool, 3-D modelling and visualisation can offer new ways in addressing thes issues affecting Ampang Jaya. Various scenarios can also be generated to study the urban impact with different sets of design parameters. As analytical tool to study the growth and spatio-temporal transformation of Ampang Jaya in 50 years since 1900, it will demonstrate and evaluate attributes of Ampang Jaya by adopting the Community Taxonomy (Florida House Institute, n.d.), according to four layers: social, economic, natural and the built environment. The interactive visualisation viewer in $\operatorname{ArcGlobe}{ }^{\circledR}$ will offer a more meaningful understanding of Ampang Jaya, highlighting its urban layers that would otherwise be limited to the form of 2-D abstract data.

Growth patterns of the city will be traced, displaying the current scenario as well as past development involving historical, environmental and large scale settlement patterns. By understanding the past and the present situation and analysing spatio-temporal transformation of Ampang Jaya, users can measure growth patterns of land use, neighbourhood and regional transportation planning, 
Mimi Zaleha Abdul Ghani, Yazid Sarkom, \& Zalina Samadi

Developing a 3-D GIS Model for Urban Planning. Case Study: Ampang Jaya, Malaysia

landscaping and site planning. This will enable people to visualise the future urban patterns and forecast the future direction of Ampang Jaya. As a predictive modelling tool, it will offer a new way to look at the past, present and future of Ampang Jaya than what is currently only available from photographs and written text (Figure 1).
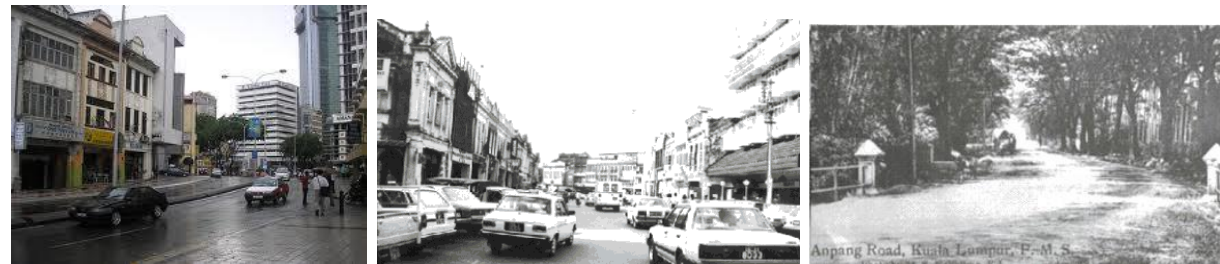

Figure 1: The development of Ampang Jaya. (Left) In the early 1900's.

(Middle) In the 1960's. (Right) In the 2000's

The process of conducting the studies will provide a better understanding for local authorities in planning practices. The empirical knowledge of developing a 3-D GIS model from the studies in Malaysia will reflect on the existing challenges, mainly involving the local authorities including available data, resources and mindset. This will perhaps suggest a more practical use of the powerful 3-D GIS programmes equipped with large automated functions for subsequent digital models of towns and cities in Malaysia, facilitating research in the area of urban design and planning.

\section{Data Acquisition, Reconstruction and GIS}

In constructing the virtual Ampang Jaya, the steps will involve acquiring and analysing spatial information through digital means to explore an interactive virtual environment for Ampang Jaya to evaluate the virtual model for urban analysis. It will investigate the techniques of data acquisition, data reconstruction from physical to digital, urban analysis and visualisation. Data acquisition on a higher scale will attempt photogrammetric technologies or 3-D laser scanning from point cloud, such as airborne Light Detection and Ranging (LIDAR), to obtain GIS data and to determine height and building details. For an economical but less accurate approach, data acquisition could rely on the current GIS datasets in MapInfo® and satellite images in Quick Bird ${ }^{\circledR}$ (of up to 0.6 meter resolution) that are readily available from the local authority. Past aerial photographs of Ampang Jaya dating from 1950 to the current date will be accessed from the Malaysian Survey and Mapping Department (JUPEM). Old topographic maps, cadastral maps, street photographs and past buildings, road system and other past information of the city will be sought from the local authority's and libraries' archives. These aerial photographs will be scanned and undergo photogrammetric processes to produce a geo-referenced image or digital orthophoto. This 
PLANNING MALAYSIA

Journal of the Malaysia Institute of Planners (2018)

orthophoto will generate the contour and Digital Terrain Model (DTM) that will provide the base map with real topographic structure and heights.

\section{3-D Modelling}

Traditional geometric constructions used by architects are generally based on CAD packages such as AutoCAD®, 3-D Max ${ }^{\circledR}$ which can offer highly precise geometries. The development from physical form to digital data for Ampang Jaya using GIS database and software is contrary to the traditional methods of geometric constructions used in city modelling. 3-D CAD models are often loaded with geometrical details, are heavy, require good operating skills and are time consuming to create. They also do not necessarily guarantee a high level of realism, defined as the mimicry of the physical environment in a virtual setting, as compared to accuracy, defined as correctness of the information utilised, modelled and depicted (Pietsch 2000). On the other hand, modelling methods such as texture mapping are inexpensive and can add realism to the virtual models displaying details in colour, texture and material. Rapid modelling usually utilise texture mapping, from oblique aerial, terrestrial images and panoramic image capturing.

In the last decade, GIS and remote sensing packages such as ArcGIS ${ }^{\circledR}$ and ERDAS ${ }^{\circledR}$ have been extended to generate 3-D content. The proposal for Ampang Jaya could employ the construction process integrating GIS and 3-D as outlined by Salleh (2008) using ArcGIS® desktop software with Sketch-Up® as the modelling software. Sketch-Up® is generally the preferred modelling software for its short learning curve and user friendliness which are essential for modelling process. Currently, ArcGIS ${ }^{\circledR}$ is mostly compatible with Sketch-Up ${ }^{\circledR}$ in complementing with details while maintaining spatial references. Orthophoto that has been imported from ArcScene and ArcMap will be locked at the actual geographic location. Spatial referencing is a distinctive attribute in a modelling software and can be carried out using Shape-file ${ }^{\circledR}$ importer; a plug-in for GIS in Sketch-Up®. This proprietary plug-in enables detailed content to be included, which is entirely compatible to the analytical functionalities and querying capabilities of state-of-the-art GIS. While the objects are geo-referenced, it can also animate scenes, perform multiple spatial queries, view shed and shadow analysis, and various scenario based analysis. Using Sketch-Up®, digitised orthophotos of Ampang Jaya will be extruded into a 3-D model while carrying attribute data. A 3-D model of Ampang Jaya from year 1950 will be developed from the 2-D GIS data layers; social, economic, built form and natural. Other objects, including roads, landscaping elements and street furniture may be incorporated at the actual locations on site. 
Mimi Zaleha Abdul Ghani, Yazid Sarkom, \& Zalina Samadi

Developing a 3-D GIS Model for Urban Planning. Case Study: Ampang Jaya, Malaysia

\section{Visualisation}

The visualisation model will incorporate a movie of growing Ampang Jaya, displaying qualitatively and quantitatively responsive spatial data information on a time-line. While modelling software such as Sketch-Up® have enhanced their functions to incorporate geospatial and interactive visualisation, GIS software are becoming more actively engaged in virtual cities. The visualisation can be recorded and played in Windows Media Player ${ }^{\circledR}$ or Quick Time ${ }^{\circledR}$, or further extended into VRML player such as Canoma ${ }^{\circledR}$. Visualisation with GIS provides a new approach to urban design and planning in dealing with the problems of site location, large settlement design and community planning, public participation and a myriad of possibilities for offering solutions. Visualisation growth of Ampang Jaya will attempt to animate data layers through spatio-temporal; space and time animation and simulation in ArcMap, ArcScene and ArcGlobe to understand how they change with space and time. However, the data availability is a huge challenge in Malaysia, compared to the experience of other cities like Kyoto in Japan which had old topographic maps (Yano et al., 2006).

\section{Data Layers}

Data layers (Table 1) will be animated in ArcScene and ArcGlobe incorporating real time, where simulation scenes will be viewed by users from different angle and height, while users will be allowed to select or hide layers as they navigate through the scene (Figure 2). 2-D map tracking can be viewed simultaneously in ArcMap® to keep users on track.

Table 1: Data layers

\begin{tabular}{ll}
\hline Layer & Data \\
\hline Social & $\begin{array}{l}\text { Indicate communal spaces and its serviceability to other parts of } \\
\text { the city. }\end{array}$ \\
Economic & $\begin{array}{l}\text { Animate large scale settlement growth, commercial and business } \\
\text { centres to understand the pattern. }\end{array}$ \\
Built form & $\begin{array}{l}\text { Animate the building development to understand the population } \\
\text { increase and boundary changes. } \\
\text { Natural }\end{array}$ \\
Animate the changes in the landscape and forest encroachment due \\
to building development.
\end{tabular}




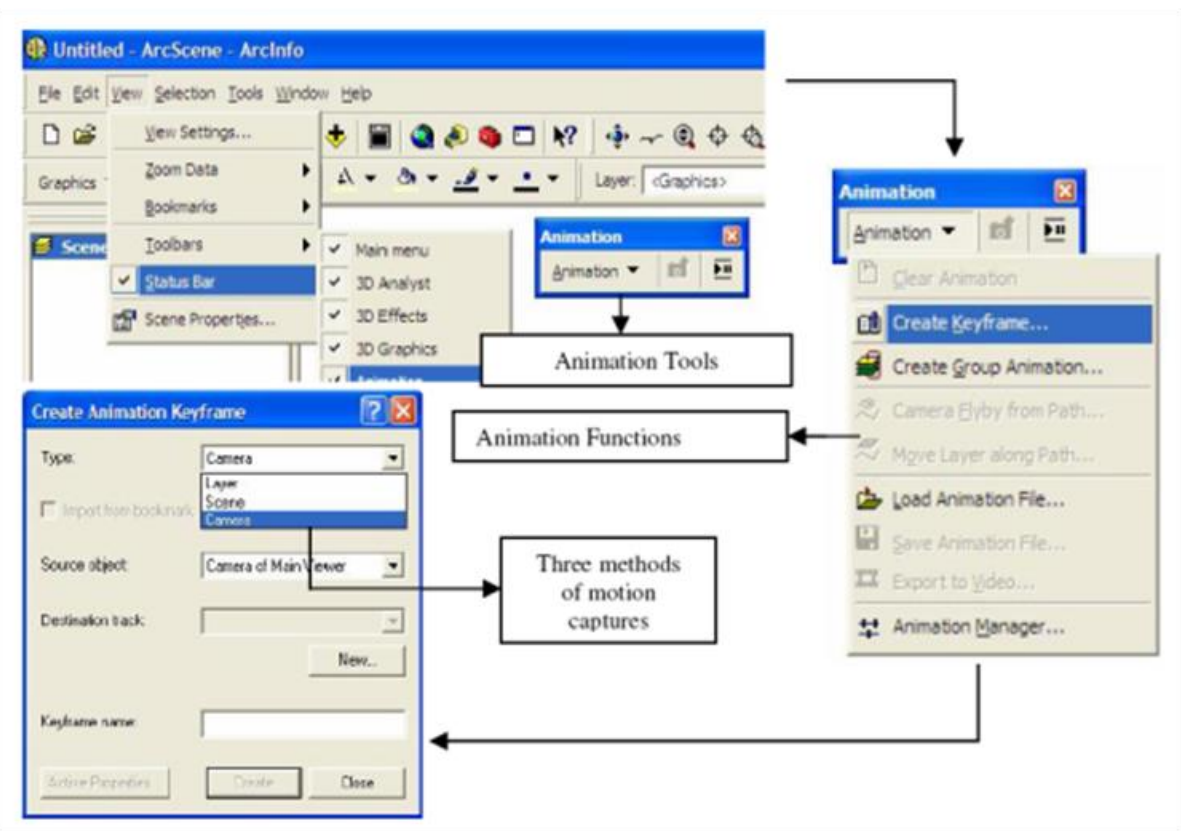

Figure 2: Example of animation development in ArcScene ${ }^{\circledR}$ Source: Salleh (2008)

\section{CASE STUDY: AMPANG JAYA}

\section{Urbanism}

Ampang Jaya in Malaysia, like other Southeast Asia cities facing urban challenges of concentration of population and poor environment (Thuzar, 2012), is experiencing economic dynamism with uncontrolled rapid growth that has sprouted beyond the limits of its urban structure, placing the local authorities and stakeholders in a dilemma. Over the last few years since its development in the early 1990s, Ampang Jaya has transformed from a quiet town into becoming a chaotic and a dense place with uncontrolled hillsides development, emergence of foreign towns as well as immense traffic and parking problems as shown in Figure 3 and 4. Changes in the physical environment in Malaysia continue to disturb the urban fabric and alter its sense of place (FDTCP, 2006). Often, changes in the physical setting, the types of uses and the streets' activities would wipe out what is special and significant to the existing individuals and the community, specifically those who have lasting connection to the areas (Shamsuddin \& Ujang, 2008). These changes in Ampang Jaya have affected the local community as they feel that Ampang Jaya has lost its sense of place. 
Mimi Zaleha Abdul Ghani, Yazid Sarkom, \& Zalina Samadi

Developing a 3-D GIS Model for Urban Planning. Case Study: Ampang Jaya, Malaysia
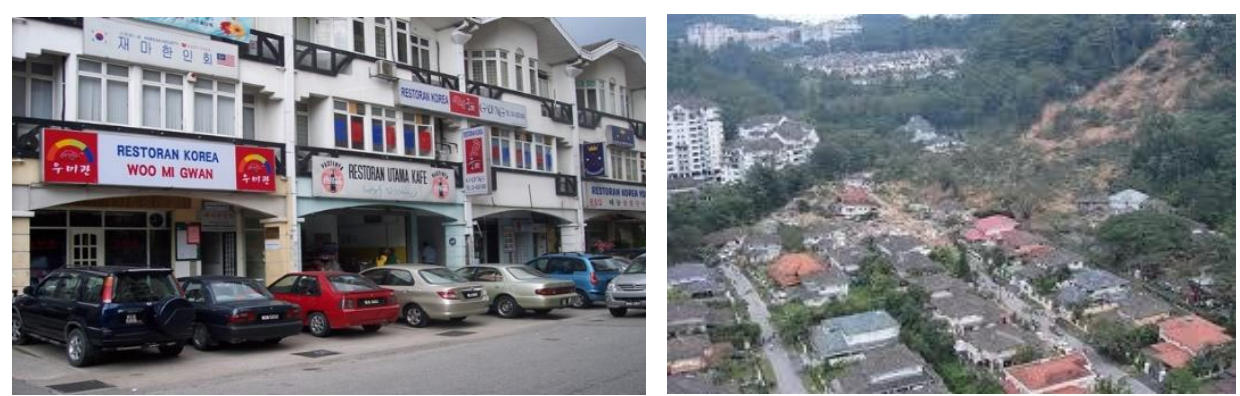

Figure 3: (Left) Little Korea. (Right) Hillside development in Ampang Jaya

While the authorities seek for a more comprehensive and meaningful information concerning Ampang Jaya in preparing them in dealing with the current issues and challenges (Ampang Jaya Municipal Council, 1998), the public are demanding more transparency in the planning processes. Apart from public pressure and the urge to gain public confidence, the local council is setting out to reorganise its planning and have a better control of Ampang Jaya.

The one-way traffic road system with ticket kiosks in the business district of Ampang Jaya was designed to replace the two-way system, aimed at reorganising the business areas while resolving the problems involving the sprawling stalls of petty traders. However, this new system results in winding traffic routes as it forces traffic to circle the business hubs and encourage business activities. Massive traffic congestion occurs when long queue of vehicles form along the parking booths as people are trying to pay for their parking tickets and obstruct the traffic flow. After just two years into installation, the authority has found the system ineffective and cannot cope with the increasing volume of traffic within the area. To resolve this, the authority has installed payment machines along the parking spaces to replace the parking booths. However, the one-way traffic route has not been revised to accommodate the new payment system. To make matters worse, illegal businesses soon made their way to fill the vacant booths, adding to the already chaotic traffic condition.
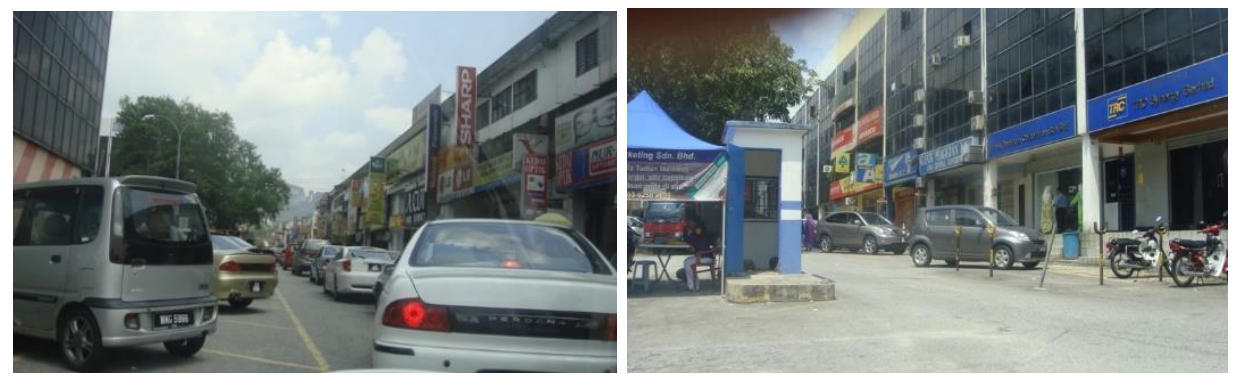

Figure 4: (Left) Traffic congestion along the one-way-traffic route. (Right) idle parking booth beside the new parking machine. 
PLANNING MALAYSIA

Journal of the Malaysia Institute of Planners (2018)

\section{Data Acquisition, Processing and Reconstruction}

Like the majority of the local planning authorities in Malaysia which use GIS's MapInfo program, authors were provided the GIS dataset in MapInfo data format (.TAB) that contains restricted data on land use and building lot parameter that covers approximately an area of 20 kilometre wide under the jurisdiction of the Ampang Jaya Municipal Council. The satellite images provided by the local council is considerably poor in resolution compared to those from the Malaysian Survey and Mapping Department (JUPEM). Although detailed current topographic maps, cadastral maps, road system and other information of the city are readily available from the local council, other data layers from relevant departments are insufficient. Past information from the local council's archive is scarce as the local council is a reasonably new municipal. Additional information such as the draft of the amended local plan and other planning documents provide authors with support materials for model development. Authors also carried out photographing the building blocks and the immediate surroundings of a selected commercial area of Ampang Jaya for the purpose of texture detailing. As illustrated in Figure 5, the project utilises ArcGIS desktop software version 9.3, including its components: ArcCatalog, ArcMap and its visualisation tool; ArcScene. SketchUp ${ }^{\circledR}$ is the preferred modelling software for its integrated functionality and compatibility with ArcGIS although its rendering and detailing capability is slightly compromised when compared with several other powerful CAD software.

3-D GIS block model may be automatically generated in ArcScene by extruding building footprints with the height data of each building stored in the GIS building height layer. However, in the case of insufficient data layer, authors develop the entire building blocks using SketchUp®. Since the data only contain the land plot, each building footprint needs to be carefully digitised from the satellite image and its height determined from the shadow cast. Figure 6 demonstrates the process of modelling a block in SketchUp®; from a polygon that has been exported using the Shape-file importer in ArcScene. Elevation photographs are meticulously edited in Adobe Photoshop before they are draped over the building blocks to create a photo realistic image of a row of shop-office. The textured blocks are then exported back into ArcScene for visualising the entire buildings within a realistic site context of the satellite image. Switching between layers from the basic and the textured block enables users to visualise the massing component of the building in relation to the realistic view. 
Mimi Zaleha Abdul Ghani, Yazid Sarkom, \& Zalina Samadi

Developing a 3-D GIS Model for Urban Planning. Case Study: Ampang Jaya, Malaysia
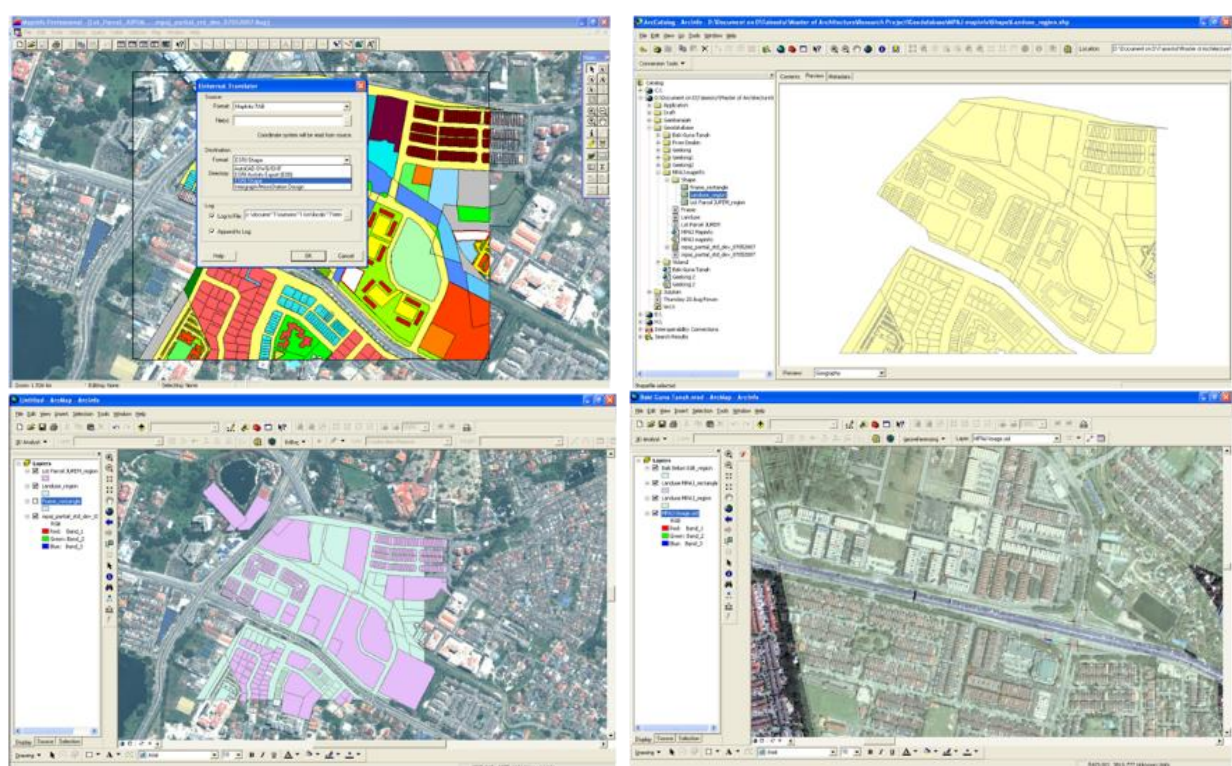

Figure 5: Data conversion from MapInfo to ArcGIS
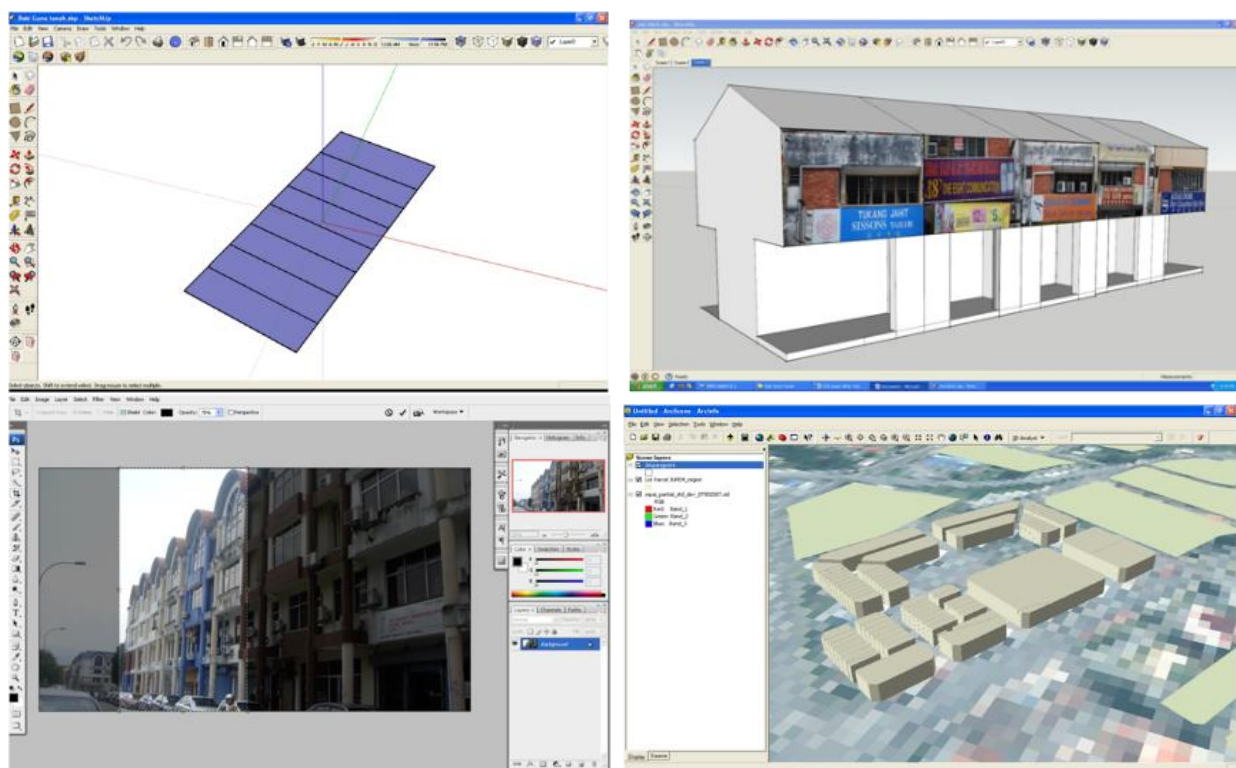

Figure 6: Development of 3-D GIS model.

\section{Analysis and Outcome}

Conducting traffic analysis involves field surveys and reports using charts, 2-D maps and drawings, and can be quite difficult, particularly when having to 
consider the various urban fabrics of Ampang Jaya. GIS visualisation enables the traffic engineers to predict the pattern of traffic flows in context of the current surrounding buildings (Figure 7), as well as the planned future buildings using 2D ArcMap. Using its 3-D component in ArcScene, the traffic information is further translated into easily understood form as it merges with spatial 3-D visualisation. As a common tool, it provides the spatial platform to merge building information from the Building Department of the local council with the road and traffic information from the Engineering Department of the council to be further discussed among relevant agencies such as the Road and Works Department, the Traffic Department, the Police Force and the stakeholders that include the shop owners and the affected public.
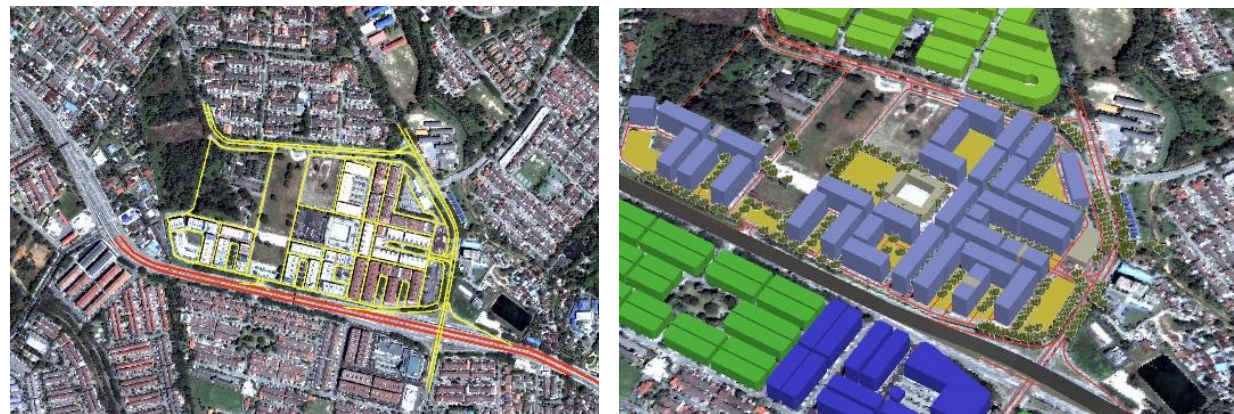

Figure 7: The 2D view of traffic route marked in red and yellow lines in ArcMap. The $3 \mathrm{D}$ view of traffic and parking system in ArcScene

The outcome of the study is expected to support planning decisions and facilitate consultation processes between councils and stakeholders and improve the dissemination and management of spatial information about urban environments. Reframed in a virtual setting, the interactive model has the potential to attract public participation and to develop better understanding among the public about their city. As the web is becoming a common platform for the wider audience, it can provide the interface for Virtual Ampang to disseminate up-to-date planning information as well as to communicate current issues and future plans while generating feedback from the general public.

\section{CONCLUSION}

In addressing both urbanism and technological demand, this paper explores the idea of developing a 3-D GIS model to address the needs for modelling urban growth (Brail \& Klosterman, 2001; Fragkias \& Seto, 2007). The expected outcome of Virtual Ampang Jaya is to support planning decisions and facilitate consultation processes between councils and stakeholders, and improve the dissemination and management of spatial information about urban environments. Involving the local authorities, it provides an insight on how to develop the model 
Mimi Zaleha Abdul Ghani, Yazid Sarkom, \& Zalina Samadi

Developing a 3-D GIS Model for Urban Planning. Case Study: Ampang Jaya, Malaysia

by translating easily understandable spatial information enabling a more comprehensive understanding of Ampang Jaya and helping bridge the gap between different professionals for better planning outcomes. Adopting 3-D modelling and visualisation also correlates with the call for electronic government (e-govt), a flagship application of the Multimedia Super Corridor (MSC) project that aims to redesign the system of the government to bring about fundamental changes from the society level (Lee \& Ahmad, 2000), as well as meeting global information technology expectations and future challenges. While it may provide as a guideline for the use of computing in planning for the authorities in Malaysia, the model can be further developed into a prototype that may incorporate GeoImmersive videos into GIS environments. Its use for modelling different scales of urban development can also suggest the appropriate hardware and integration of software that are deem suitable.

While Virtual Ampang Jaya attempts to explore the GIS analytical and querying capabilities with interactive visualisation environment, the case study is an infant project in testing the model for analysis that integrates $\mathrm{CAD}$ with limited application of GIS software with the available data commonly maintained by planning authorities in Malaysia. Its effectiveness for urban and planning analysis is heavily challenged by many factors, primarily data availability and accuracy that includes lack of data layers and substandard satellite image. As a result of these, several automated tools designed to facilitate the process cannot be explored, for example, the extrusion technique in ArcScene. Lack of resolution in the satellite image has made it ineffective to conduct 3-D analysis of the buildings in context of its surroundings as the pixelated ground image from perspective views hardly represents a virtually realistic environment.

Another issue that challenges this project is the disciplinary boundary that demands expertise from firstly, the modelling capability that is often related to the architects, and secondly, the GIS software application that are often used by planners. The third expertise which involves geo-referencing; the forte of the land surveyors, may overcome our deficiency as a higher resolution image can be "stitched" and geo-referenced from the Google Maps. While the future of 3-D visualisation and GIS is encouraged by the integration of these expertise, the current developments of GIS among the planning authorities in Malaysia are positive with the support from the Federal and State Town Planning Departments. The future 3-D GIS model will aim to explore GIS's powerful analytical and querying capabilities within the interactive visualisation environment while experimenting future possibilities with "urban parametric". Integrating the evolving technologies in retrieval, transmission and visualisation of 3-D data, it will attempt the future virtual world that is capable of constantly and relatively changing alongside the real world. 


\section{ACKNOWLEDGEMENT}

We would like to thank the staff from the Planning and Building Departments of the Ampang Jaya Municipal Council for the contribution of information and data used in this research.

\section{REFERENCES}

Abdullah, M. F., Abdullah, A., \& Ibrahim, M. (2009). Institutionalisation of spatial planning and decision support system for planning and governance in Malaysia. In A. Abdullah \& D. Geneletti (Eds.), Spatial decision support for urban and environmental planning: A collection of case studies (pp. 153-166). Shah Alam, Malaysia: Arah Publications.

Ampang Jaya Municipal Council (1998). Ampang Jaya Structure Plan 1995-2020. Selangor: Author.

Arribas-Bel, D., Kourtit, K., Nijkamp, P., \& Steenbruggen, J. (2015). Cyber Cities: Social media as a tool for understanding cities. Applied Spatial Analysis and Policy, 8(3) 231-247.

Batty, M. (2012). Smart cities of the future. The European Physical Journal Special Topics, 214(1), 481-518.

Brail, R. K., \& Klosterman, R. E. (2001). Planning support systems: Integrating geographic information systems, models and visualization tools. California: ESRI Press.

Florida House Institute (n.d.). A framework for vision-based planning: A taxonomy for communities. Florida: Author.

Fragkias, M., \& Seto, K. C. (2007). Modeling urban growth in data-sparse environments: A new approach. Environmental and Planning B: Planning and Design, 34, 858 883.

Herbet, G., \& Xuwei, C. (2015). A comparison of usefulness of 2D and 3D representations of urban planning. Cartography and Geographic Information Science, 42(1), 22-32.

Federal Department of Town \& Country Planning Peninsular Malaysia [FDTCP] (2006). National urbanisation policy. Malaysia: Author.

Lee, L. M., \& Ahmad, M. J. (2000, March). Local authority networked development system. Planning Digital Conference. March 28-29, 2000, Penang, Malaysia.

Lopes, C. V., \& Lindström, C. (2012). Virtual cities in urban planning: The Uppsala case study. Journal of Theoretical and Applied Electronic Commerce Research, 7(3), 88-100.

Pietsch, S. M. (2000, September). The pursuit of realism in urban visualisation models. Habitus 2000. September 5-9, 2000, Perth, Australia.

Rafi, A., \& Rani, R. M. (2008, May). Visual Impact Assessment (VIA): A discussion on computer-based methodologies used for urban streetscapes. International Conference on Environment Research and Technology (ICERT 2008). May 2830, 2008, Penang, Malaysia.

Rong, D. Wu, P., \& Shang, J. (2017). A practical method for the construction of urban 3D GIS and its application. Revista de la Facultad de Ingenieria UCV, 32(3), 279-287. 
Mimi Zaleha Abdul Ghani, Yazid Sarkom, \& Zalina Samadi

Developing a 3-D GIS Model for Urban Planning. Case Study: Ampang Jaya, Malaysia

Salleh, S. A. (2008). The integration of 3D GIS and virtual technology in the design and development of GIS-based residential property marketing information system (Master thesis). Universiti Teknologi MARA, Shah Alam, Selangor, Malaysia.

Shamsuddin, S., \& Ujang, N. (2008). Making places: The role of attachment in creating the sense of place for traditional streets in Malaysia. Habitat International, 32(3), 399-409.

Shiffer, M. J. (1993, October). Augmenting geographic information with collaborative multimedia technologies. 11th International Symposium on Computer-Assisted Cartography (Auto-Carto). October 30- November 1, 1993. Minneapolis, Minnesota, USA.

Sunesson, K., Allwood, C. M., Paulin, D., Heldal, I., Roupé, M., Johansson, M., \& Westerdahl, B. (2008). Virtual reality as a new tool in the city planning process. Tsinghua Science and Technology, 13(S1), 255-260.

Thuzar, M. (2012). Urbanization in Southeast Asia: Developing smart cities for the future? In M. J. Montesano \& Lee P. O. (Eds.), Regional Outlook: Southeast Asia 2011-2012 (pp. 96-100). Singapore: ISEAS Publishing.

Yano, K., Nakaya, T., Isoda, Y., Takase, Y., Kawasumi, T., \& Matsuoka, K. (2006, August). Kyoto Virtual Time-Space. Annual ESRI International User Conference. August 7-11, 2006, San Diego, California, USA. 